\title{
The Use of Differing Verb Types in the Oral Narratives of School- Age Children
}

\author{
Allison Ann Switzer \\ aaswitzer@mix.wvu.edu
}

Follow this and additional works at: https://researchrepository.wvu.edu/etd

Part of the Speech Pathology and Audiology Commons

\section{Recommended Citation}

Switzer, Allison Ann, "The Use of Differing Verb Types in the Oral Narratives of School-Age Children" (2020). Graduate Theses, Dissertations, and Problem Reports. 7519.

https://researchrepository.wvu.edu/etd/7519

This Thesis is protected by copyright and/or related rights. It has been brought to you by the The Research Repository @ WVU with permission from the rights-holder(s). You are free to use this Thesis in any way that is permitted by the copyright and related rights legislation that applies to your use. For other uses you must obtain permission from the rights-holder(s) directly, unless additional rights are indicated by a Creative Commons license in the record and/ or on the work itself. This Thesis has been accepted for inclusion in WVU Graduate Theses, Dissertations, and Problem Reports collection by an authorized administrator of The Research Repository @ WVU. For more information, please contact researchrepository@mail.wvu.edu. 
The Use of Differing Verb Types in the Oral Narratives of School-Age Children

Allison Switzer, B.S.

Thesis submitted to the College of Education and Human Services

at West Virginia University

in partial fulfillment of the requirements for the degree of

Master of Science

in Speech-Language Pathology

Jayne Brandel, Ph.D., Chair

Michelle Moore, Ph.D.

Alexandra Hollo, Ph.D.

Department of Communication Sciences and Disorders

Morgantown, West Virginia

2020

Keywords: school-age, narrative discourse, verbs, language impairment, typical language

Copyright 2020 Allison Switzer 


\section{ABSTRACT \\ The Use of Differing Verb Types in the Oral Narratives of School-Age Children}

\section{Allison Switzer, B.S.}

The aim of this project was to examine the use of action, metacognitive, and metalinguistic verbs in narratives relative to age-related growth for children with typical language and their peers with a language-based disorder. While limited information is known about the use of these differing verb types, there is evidence to show that metacognitive and metalinguistic verbs are less salient than action verbs, and therefore have a longer trajectory of acquisition. The oral narratives of 84 typically developing students were coded for occurrences of action verbs, metacognitive verbs, and metalinguistic verbs to obtain a total use as well as to examine the number of different verb types in each category used by the participants. In addition, the use of these verbs by 76 children with typical language were compared to those of 38 age-matched children with language impairment. The results indicated that an increase in age lead to a significant increase in the number of action, metacognitive, and metalinguistic verbs used. The findings also revealed that children with typical language used a wider variety of verbs in their narratives as compared to those with a language-based disorder. 


\section{Acknowledgements}

I would like to sincerely thank my thesis mentor, Dr. Jayne Brandel, for her tremendous support and guidance throughout this project and actually, throughout my entire experience at West Virginia University. It has been a privilege to be her graduate assistant for the past two years. Dr. Brandel has provided me with an abundance of knowledge and experience that has allowed me to grow and become a better researcher and clinician. I could not have completed this process without her help, so I am truly grateful for all that she has done.

I would also like to thank my thesis committee members, Dr. Michelle Moore and Dr. Alexandra Hollo. I am so appreciative of the time and effort they have both contributed to my thesis. Their direction and feedback have been crucial to the success and completion of this project, and I truly value all of their help. Lastly, I would like to thank David Loomis for his invaluable advice and expertise regarding the statistical analyses. 


\section{Table of Contents}

Chapter I: Introduction and Review of Literature ........................................1

Acquisition of Action Verbs ...................................................... 3

Acquisition of Metacognitive and Metalinguistic Verbs ..............................5

Figure 1 .................................................................... 6

Use of Verbs in Narrative Discourse ............................................. 10

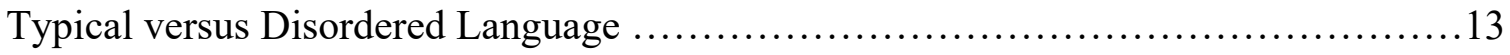

Chapter II: Present Study .................................................................. 16

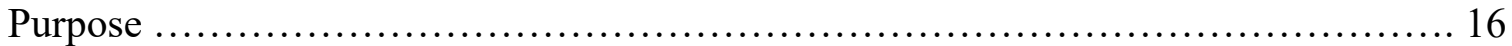

Chapter III: Methods ................................................................... 17

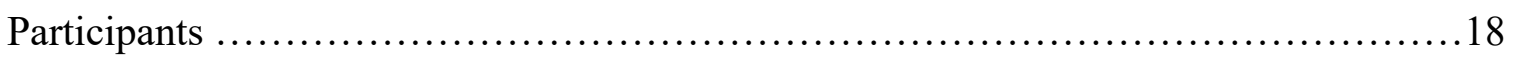

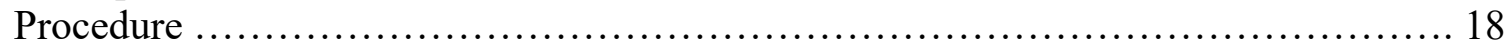

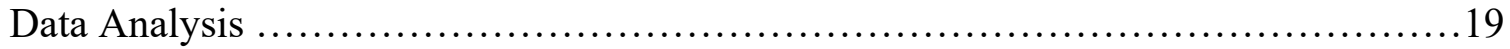

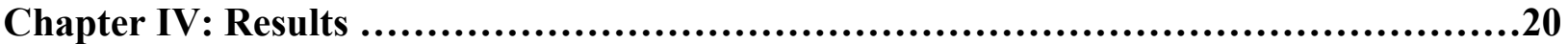

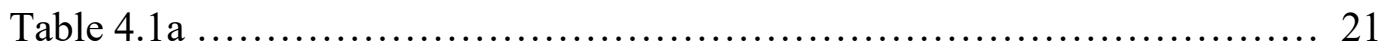

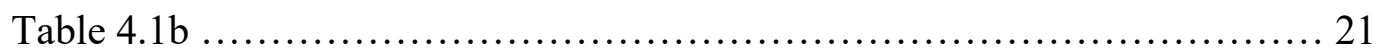

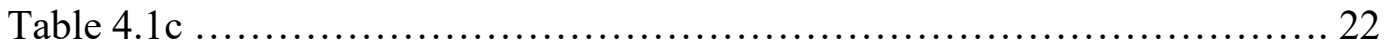

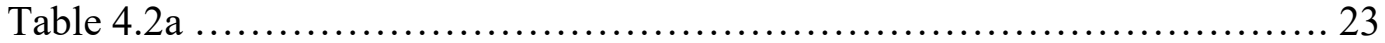

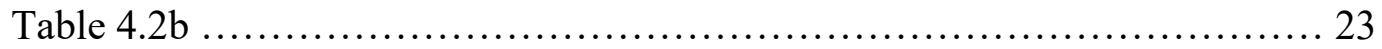

Research Question One ....................................................... 24

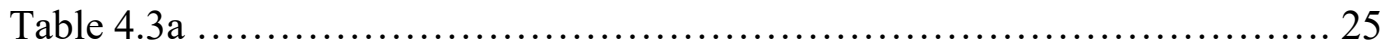

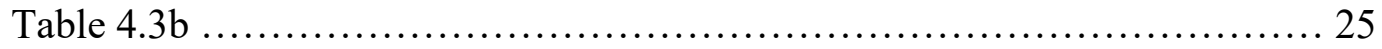

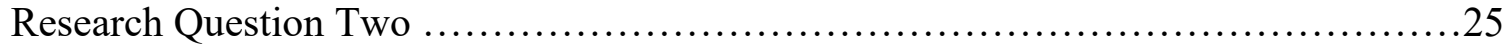

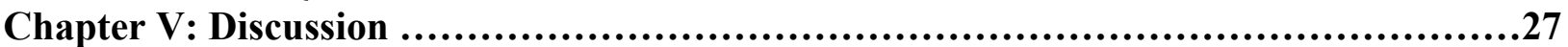

Verb Development and Use by Students with Typical Language and Disorders ........ 28

Clinical Implications ............................................................. 29

Limitations and Future Research ............................................ 30

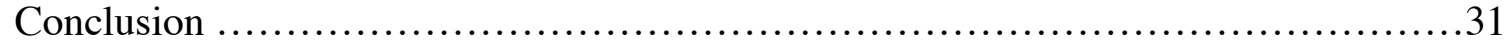

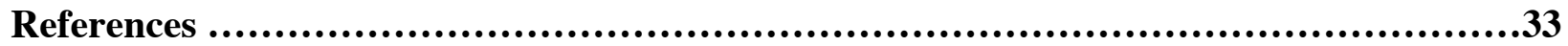




\section{Chapter I: Introduction and Review of Literature}

Narrative discourse has become increasingly prevalent in the curriculum of the publicschool system. Students who possess the language skills involved in this genre are more likely to succeed in the late elementary and early middle school years (Gillam and Johnston, 1992; Nippold, 2016; Sun \& Nippold, 2012). Evidence of this expectation for narrative proficiency is reflected in the Common Core State Standards such as those directly related to the ability to selfconstruct and retell narratives. For instance, the third writing standard for grades 6-12 states that students will "write narratives to develop real or imagined experiences or events using effective technique, well-chosen details, and well-structured event sequences" (Common Core State Standards, 2010). To effectively accomplish this task, a student would need to know and organize sequentially the parts of a narrative. Developing narratives also requires sentence construction of various complexities. In order to accomplish this, the student would need to accurately utilize adjectives and adverbs to describe characters, settings, and events as well as integrate phrases and words which connect the sentences and paragraphs cohesively using compound or complex sentences, requiring the use of coordinating and subordinating conjunctions. Therefore, narrative discourse incorporates the use of a variety of complex language structures.

Beyond the language structures related to word types and syntax, narratives also incorporate literate language, commonly referred to as decontextualized language. Decontextualized language encompasses language structures that are not concrete in their definition and require a more sophisticated level of syntax and cognitive reasoning to fully understand the concept being semantically represented. These language structures are important for listening and reading comprehension and are often embedded within elaborated noun phrases, 
adverbs and adverbial phrases, or polysemous terms in stories (Nippold, 2016; Justice \& Ezell, 2016). The use of these more complex structures is what differentiates narrative discourse from simple conversation, making it more academically relevant. Since decontextualized language is more abstract, development of these structures used in narratives coincides with one's development of theory of mind, defined as the ability to predict one's own and other's behaviors based upon mental states (Valle et al., 2015). More clearly stated, theory of mind is related to one's ability to understand mental states and be aware of other's thoughts, feelings, and perspectives that differ from their own.

Included in the decontextualized language structures observed in narrative discourse are metacognitive and metalinguistic verbs. Metalinguistic verbs include words that refer to acts of speaking (e.g. said, exclaim, tell). Similarly, words utilized to describe the cognitions often include metacognitive verbs, which are those that refer to acts of thinking (e.g. decide, guess, know) (Nippold, 2016). The acquisition of these verbs is dependent upon the development of theory of mind and the use of these verbs in narratives is crucial in order to initiate dialogue and describe the characters' feelings, thoughts, and inner reactions. Due to their role in narrative discourse, metalinguistic and metacognitive verb competencies require an interaction between cognition and language and could influence students' success in school related to advanced language skills such as reading and writing (Nippold, 2016; Schwanenflugel \& Henderson, 1998).

Also included in the language structures incorporated in narrative discourse are action verbs. Action verbs are considered contextualized language and are more concrete than mental and linguistic verb types, meaning their acquisition is more dependent upon mere exposure and word mapping. However, action verbs still play a large role in the organization and construction 
of narratives. Altogether, the use of these three verb types, action verbs, metacognitive verbs, and metalinguistic verbs contributes to both the quality and complexity of students' selfconstructed stories and narrative retells.

\section{Acquisition of Action Verbs}

While action verbs are developed later than most concrete nouns, this verb type typically comprises a child's early lexicon, developing rapidly throughout a child's second year of life (Justice \& Ezell, 2016; Papafragou et al., 2007; Golinkoff \& Hirsh-Pasek, 2008). From the very early stages of development, infants are drawn to motion and are able to attend better to objects in motion rather than those that are static. As a result, interpreting events and actions is a large part of early cognitive stages and crucial to a child's conceptual system as well as language learning. One study by Hirsh-Pasek \& Golinkoff (2006) supported this idea when evaluating how 15-month-old children identified a ball. The results of their study indicated that while balls were first identified on the basis of shape, most children made their final decision based upon whether or not the "ball" would roll. These results indicated that the understanding of actions was significant in the early stages of life as children acquire language.

The majority of research on action verb learning refers to many different proposed hypotheses instead of one strict, typical acquisition pattern. Hirsh-Pasek \& Golinkoff (2006) concluded that prerequisites for verb learning include forming the category of actions along with the language component of mapping the actions to words. Some evidence has shown that verbs are first learned as single units before they are placed into an overall category. As more verbs are acquired, children are able to observe a pattern in the syntactic use (i.e., all words relate to actions or states of 'doing') (Owens, 2016). The second part of verb learning mentioned, a concept of word mapping, is harder for children when learning verbs as compared to nouns 
because verbs are considered "relational," meaning there is an entity required to take form of the action. For example, a person is required to carry out the action of "running" for this term to be learned as a verb and to be understood by the child (Golinkoff \& Hirsh-Pasek, 2008). Therefore, word mapping requires the learner to observe the action verb as it is happening to understand the concept being conveyed.

Just as word mapping and perceptual information play important roles in verb development, there is evidence indicating that social information also aids in the process of language learning and comprehension of action verbs (Akhtar \& Tomasello, 2000). For instance, social cues such as discerning a person's true intent are needed to ensure full comprehension of some verbs. Since verbs are more transient than concrete nouns, children are not able to make the same associations between an object and an object label. Therefore, in order to fully comprehend this type of action verb, toddlers should be exposed to these verbs within social contexts where they must use social pragmatic cues and event knowledge to decide if the communication partner meant to perform the said action or if it was accidental (Akhtar \& Tomasello, 2000).

An example of this social concept of intent impacting meaning was provided by Akhtar and Tomasello (2000) related to "topple over" versus "knock over." These are two different action verbs that depend on an individual's intent. If it was malicious, the statement "He knocked it over" would be appropriate; however, if an object merely "toppled over" one can assume that it was an accident (Golinkoff \& Hirsh-Pasek, 2008). These findings support the belief that language in general, including action verbs, is acquired and comprehended best when the child is submerged in everyday situations where they are able to overhear the use of these words by adults and observe the context in which they occur. In different environments, they are able to discern a word's meaning by being exposed to multiple syntactic frames, often referred to as 
“cross-situational learning" (Akhtar \& Tomasello, 2000). This outlined research indicates that there are numerous hypotheses related to action verb development, including categorization based upon perceptual cues, word fast mapping, and social interaction.

\section{Acquisition of Metacognitive and Metalinguistic Verbs}

In contrast to action verbs, there is limited research which has been completed regarding the development of metacognitive and metalinguistic verbs. It is known that metacognitive and metalinguistic verbs differ from typical verbs in a number of ways, such as their abstract properties and high frequency of occurrence in maternal speech, that is not reflected in a child's beginning vocabulary set (Papafragou et al., 2007). Additionally, these verbs have an atypical acquisition pattern as compared to typical action verbs and develop over a longer period of time due to their increased level of abstractness and reliance on an appropriately developed theory of mind (Papafragou et al., 2007; Sun \& Nippold, 2012; Nippold, 2016; Astington \& Olson, 1987). There also has been evidence to indicate that acquisition may be reliant on an individual's experiences with written language (Fuste-Herrmann et al., 2006; Curenton \& Justice, 2004, Nippold, 2016). Since literate language verbs are used to discuss abstract ideas and their comprehension is based strongly on a person's language abilities, these verbs cannot be acquired with only the use of visuals, intonation, or shared experiences that occur in conversation and social interaction, like action verbs can be (Justice \& Ezell, 2016). This development and comprehension of metalinguistic and metacognitive verbs is important for students to be able to relate to and convey awareness of characters' emotions in narratives as well as to identify the degree of certainty of their own mental states (i.e., "I know I understand" versus "I think I understand") and address the mental states of their peers in conversation (Greenhalgh \& Strong, 2001; Schwanenflugel \& Henderson, 1998). 
There are conflicting views on the reasoning for the atypical, longer acquisition pattern for metalinguistic verbs compared to action verbs. One explanation is based upon the Shape, Individuation, Concreteness, and Imaginability (SICI) continuum, in which concrete action verbs are identified to be more salient than differing verbs such as path of motion verbs and mental state verbs. This acronym was used to describe four major factors that contribute to the differing developmental paths of varying verb types: a noun or verb's shape, individuation or level of clarity, concreteness, and imaginability (Figure 1) (Hirsh-Pasek \& Golinkoff, 2006; Golinkoff \& Hirsh-Pasek, 2008).

Figure 1 SICI continuum, adapted from Hirsh-Pasek \& Golinkoff (2006) SICI Continuum

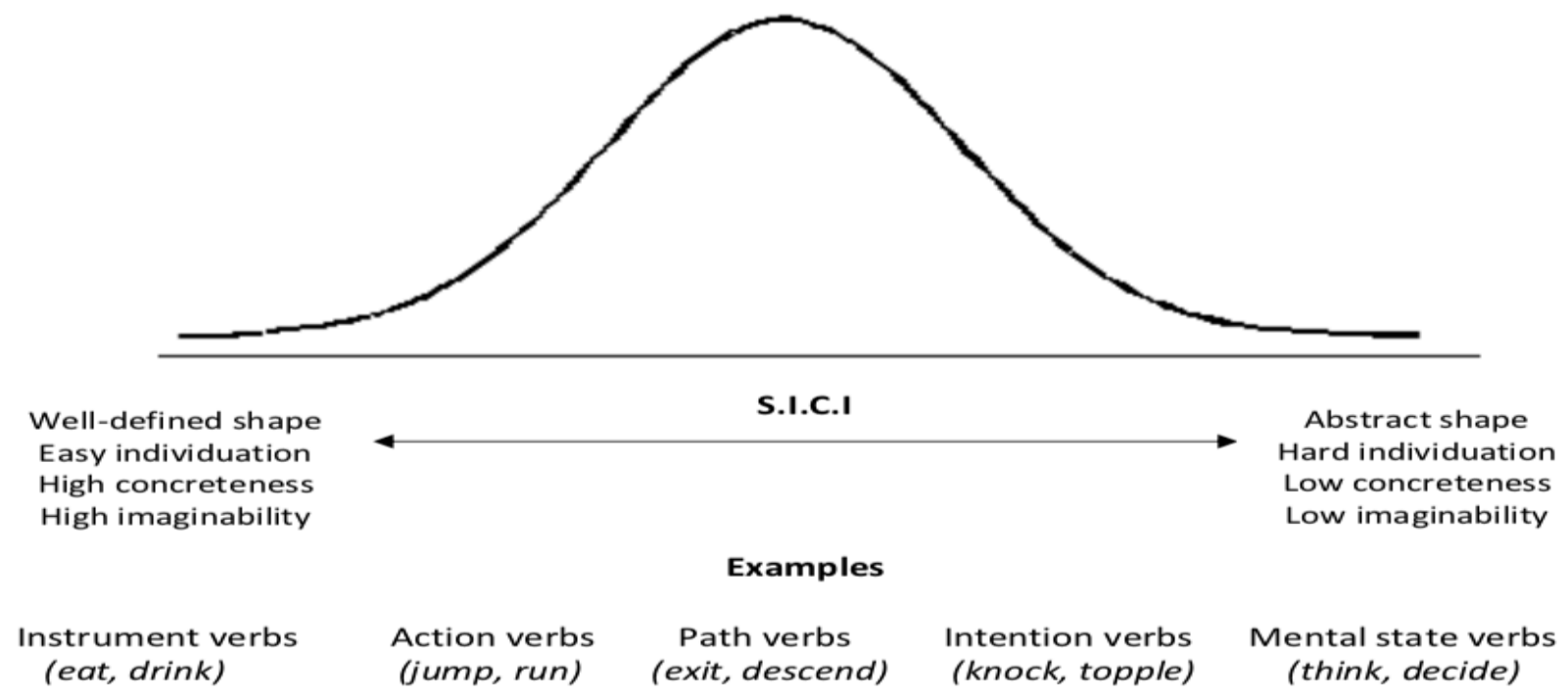

Similar to this development pattern continuum proposed by Hirsh-Pasek and Golinkoff (2006), Papafragou et al. (2007) identified two main hypotheses to explain a longer acquisition pattern, specifically in relation to metacognitive verbs. The first, the information growth hypothesis, poses that mental state verbs are acquired later in childhood due to their abstractness. 
If children acquire new vocabulary by establishing a relationship between the word and the observed elements (i.e., an action which can be seen, such as running), then it is plausible that they struggle to comprehend decontextualized language because they are not able to overtly observe the mental state verbs such as "think" and "know" (Papafragou et al., 2007). For instance, to understand the rather simple metacognitive verb "think", one has to observe secondary behaviors such as pausing movement and talking as well as having a distant look in one's eyes. These characteristics are not technically related to the action of "thinking" but rather secondary behaviors observed sometimes, but not always, when one is thinking. Therefore, unlike action verbs where the activity observed is more directly related to the word's meaning, the visual information gathered and associated with the meaning of metacognitive and metalinguistic verbs is not directly related to the word's meaning but rather with the associated behaviors that are commonly observed.

Alternatively, the conceptual growth hypothesis, proposes that the delay in acquiring these verbs was due to a lack of understanding the underlying mental concepts, those similar to theory of mind (Papafragou et al., 2007). Specifically, the ability to understand metalinguistic and metacognitive verbs requires more complex cognitive abilities. Without the ability to attribute beliefs, feelings, and intents to oneself and to others, children cannot yet acquire the words to express those thoughts. For example, if a child was unable to incorporate another individual's point of view when observing an event such as a conflict between two other people, then the child would not be able to fully understand metacognitive verbs such as, "assume," "hypothesize," or "doubt" because they are unaware of the differences which occur when interpreting the meaning of these words and phrases based upon the perspective which is being utilized to interpret the situation. As a result, the child might only hypothesize outcomes which 
align with his/her own perspective as opposed to providing more robust options which incorporate multiple points of view and possibilities.

There is additional research, similar to this hypothesis of conceptual growth, that has shown theory of mind lays a foundation for the syntactic verb class of metacognitive and metalinguistic vocabulary (Schwanenflugel \& Henderson, 1998; Schneider, 2008; Peskin \& Astington, 2004; Sun \& Nippold, 2012). Schwanenflugel \& Henderson (1998) conducted a study with participants ranging from school-age through adulthood related to the organization and understanding of cognitive verb extensions. The participants were given a mental activity scenario for which they had to choose a cognitive verb from a list that best applied to each scenario. There were verbs that were intended to fit multiple scenarios to examine the participants' organization abilities and growing theory of mind. It was concluded that there was an increase in the understanding of the role of memory input functions (e.g. examine, explore, recognize, search) and an increase in the interrelatedness of memory and cognitive related verbs with age. Their results indicated that the "constructivist theory of mind" necessary for fully developing the understanding of mental state verbs continued to develop into later childhood/early adulthood (Schwanenflugel \& Henderson, 1998). Similarly, Schneider (2008) concluded that early theory of mind competencies in young children, such as their ability to take the perspective of someone else and their ability to recognize assertions as the expressions of someone's beliefs, affected their acquisition of metacognitive vocabulary. This increased understanding of mental state vocabulary also led to an increase in their development of advanced metacognitive knowledge, such as inferential and interpretative mental abilities (Schneider, 2008). Collectively, this research indicated that acquisition of metacognitive verbs continues beyond early childhood years due to the notion that theory of mind also continues to 
develop into later adolescence and early adulthood. While a large portion of research focuses on this theory of mind explanation, there has been additional research studies to determine alternative or supplemental ways of acquisition for these verb types.

One study related to the acquisition of mental state verbs was conducted to determine if an increase in exposure to metacognitive verbs resulted in an increase in the production and comprehension of this type of vocabulary (Peskin \& Astington, 2004). In this study, half of the students were read narratives which included a high frequency of metacognitive verbs. The other half, the control group, were presented stories with no instances of mental state verbs. Following the four-week intervention, participants completed false belief batteries, a comprehension test created by Astington \& Pelletier (2003) to examine comprehension of metacognitive verbs, and an open-ended storytelling task. Results revealed that, although children who were exposed to more metacognitive vocabulary did use a higher number of metacognitive verbs in their oral story task, they did not demonstrate an improvement in the comprehension of these verbs. This evidence suggested that increased exposure to metacognitive verbs was an important factor in increasing children's use of these verbs. However, increased exposure alone was not effective in increasing children's understanding of metacognitive verbs. Rather, the authors argued that understanding of mental state verbs also relied heavily on the child's development of an appropriate theory of mind, with their ability to construct mental interpretations and focus on the mental states included in a story.

Related to previous information regarding a prolonged acquisition process of mental and linguistic verbs, research has shown that more complex emotional concepts emerge in adolescence and the in-depth understanding of literate language verbs requires more intense semantic elaboration. This rehearsal of stimulus representations results from a "slow-mapping 
process of intense and long-term experiences" through tasks such as reading and writing (FusteHerrman et al., 2006). Given this information, it would be expected that the use of literate language verbs, such as metacognitive and metalinguistic verbs, would increase with age, but the available evidence in the study by Fuste-Hermann et al. (2006) was incongruent due to the varying differences in age groups. Overall, however, the development of metacognitive and metalinguistic verbs was observed to take on a longer trajectory when compared to the acquisition of action verbs in this study and many others.

\section{Use of Verbs in Narrative Discourse}

As with most areas of decontextualized language, there is limited research on the use of action, metacognitive, and metalinguistic verbs within narrative language across different age groups. A large portion of this research field was related to multi-language learners or second language acquisition as well as populations with varying disorders. However, in general, it has been noted that action verbs largely contribute to the overall structure of narrative discourse. Van Dijk (1975) proposed that all narratives, whether conversational or fictional, could be classified as "action discourse" because action verbs and sequences comprised the structure of this language genre. Decontextualized language verbs such as metacognitive and metalinguistic verbs equally contribute to narrative discourse, most often by increasing the complexity of narratives.

Beyond action verbs, several studies have examined the use of literate language verbs. Sun \& Nippold (2012) observed significant increases for use of both abstract nouns and metacognitive verbs in children between 11,14 , and 17 years of age when completing a narrative writing task. In addition, age-related increases in language productivity and syntactic complexity were noted in the narrative writing samples. These results indicated that the development of complex language structures continued into late adolescence. Sun \& Nippold (2012) attributed 
the long developmental trajectory of these literate language features to the growth reflected in language (e.g., abstract thought, organization, perspective-taking) that was related to the development of the frontal-temporal lobes between late childhood and adolescence.

Studies similar to the one by Sun \& Nippold (2012) have also been conducted with speakers of varying languages. One study analyzed the production of mental state verbs within the context of oral narratives with English-only speaking participants, bilingual participants, and Spanish-only speaking students between the ages of nine and eleven (Fuste-Herrmann et al., 2006). The use of mental states in the oral narrative retells of Frog, Where Are You? (Mayer, 1969) were categorized into three groups: motivational, experiential, and belief. Before the narrative was presented, the children were briefed to the use of mental state verbs, and before their narrative retells, they were prompted with questions such as, "What was going on in the characters' minds?" A significant interaction between the verb types utilized, the language spoken, and the number of languages spoken was observed. The English-only speaking preadolescents used the greatest proportion of experiential and belief verbs, while motivational verb use did not differ with language status. In contrast to other studies, age was not observed to impact the performance of the different groups (Fuste-Herrmann et al., 2006). Although difference in age was not a significant variable in the use of mental state verbs, language status was observed to have a significant effect on the use of experiential and belief verbs.

In contrast to the findings of Sun \& Nippold (2012) but similar to the research of FusteHermmann et al. (2006), Greenhalgh and Strong (2001) noted that age-related growth did not have a significant effect on the use of mental verbs in oral narrative retells of the story, Frog, Where Are You? (Mayer, 1969). One hundred and four participants with and without a language disorder, seven to ten years of age, were compared based upon age, language level, and gender in 
regard to the use of conjunctions, elaborated noun phrases, mental and linguistic verbs, and adverbs (Greenhalgh \& Strong, 2001). The results indicated that there was no difference in the average use of mental and linguistic verbs across age level or language ability. Based upon these findings, changes across age levels were not observable possibly due to the small age range of the participants. The use of metalinguistic and metacognitive verbs may also be limited in oral narrative retell contexts, as opposed to self-constructed narratives or even written contexts, making it difficult to observe a difference across age groups as well as between language abilities.

An additional topic of discussion that relates to verb use in narrative discourse is the nature of the task. While there have not been any studies to examine the use of verbs across tasks of varying complexity or differing modalities, it is possible that more verbs or a wider variety of verbs would be used in a more syntactically complex task. In regard to story modality, several research studies have indicated that oral stories may be longer in the younger years with no true differences in syntactic complexity between oral and written stories, but as children get older, around secondary school-age, a greater difference in modalities is observed (Gillam \& Johnston, 1992). Fey et al. (2004) concluded similar findings to this proposition in a study that compared the oral and written language skills in the narratives of second and fourth grade children with typical language and language disorders. The authors found that most general language measures were greater for oral stories in second grade, with the most significant difference being a greater total number of T-units and number of different words. With a growth in age from second to fourth grade, gains in the written stories were significantly greater than gains in the oral stories for the measures of number of different words, total T-units, clausal density, and narrative quality (Fey et al., 2004). Additional analysis identified that these gains were similar between 
both groups, meaning that language abilities did not have an impact on the growth observed between oral and written modalities from second to fourth grade.

Along with modality of the task is the task complexity or genre variations. As measures of syntactic complexity and language productivity have been assessed in studies of modality, they have also been assessed in studies with varying genres. One study examining genre variations was conducted by Nippold et al. (2015). In this study, the syntactic complexity was compared between a conversational task and a fable critical-thinking task as well as between a narrative retell prompt and a fable critical-thinking task performed by adolescents ages $12 ; 10$ $14 ; 11$. The findings indicated that the critical thinking task about fables resulted in a significantly greater use of complex syntax when compared to the conversational task, specifically with an average of one additional clause per conversational unit. Alternatively, the narrative retelling of the fables elicited a higher mean length of utterance (MLU) than the critical-thinking fables task. Further results indicated no difference in clausal density between the narrative language and fable critical-thinking tasks (Nippold et al., 2015). This research overall indicated that differing genres and tasks may impact the use of complex syntax.

\section{Typical versus Disordered Language}

There is a large body of research that has examined the characteristics of narratives created by students with and without language-based disorders. Students with language disorders typically exhibit less complex narratives that are unorganized and underdeveloped while also containing more simple sentences (McFadden \& Gillam, 1996; Scott \& Windsor, 2000; Fey et al., 2004). One study by Reed et al. (2007) examined the differences in the retells of Frog, Where Are You? (Mayer, 1969) by adolescents ages 12;0 to 16;11 with and without specific language impairment. The individual C-units of each story were classified as either "informative," 
"vague," "inaccurate/irrelevant," or "no response" based upon the story details and events included. It was observed that the adolescents diagnosed with specific language impairment were more than three times more likely to include "irrelevant/inaccurate" details in their narrative retells. These results indicated that the narratives of adolescents with impaired language contained more utterances with information that did not pertain to the narrative or were inaccurate than those of their peers with typical language.

Related to the research of Reed et al. (2007), another study was conducted by Merritt \& Liles (1987) to examine the narrative abilities of children with typical language skills and children with language impairment, ages $9 ; 0$ to $11 ; 4$, in the contexts of story generation, retelling, and comprehension. In the story retell task, the authors observed that children with language impairments used fewer complete story episodes, a lower number of main and subordinate clauses per episode, and a lower frequency of story macrostructure elements.

In a more general observation, Scott \& Windsor (2000) found that children with language learning disabilities had significantly shorter narratives as measured by the number of utterances per story. In addition, students with language learning disabilities exhibited more difficulty producing their stories based upon the fewer words per minute and greater number of errors per T-unit. These earlier findings were supported by Fey et al. (2004), who observed that children in second and fourth grades with language impairments produced stories that had fewer different words and clauses per utterance as well as more grammatical errors than same-age peers with typical language skills.

In examining the narratives of adolescents with language impairments and same-age peers, McFadden \& Gillam (1996) used a holistic scoring approach to rate the quality of the narratives. This scoring approach rated a story's grammar, vocabulary, episodic organization, 
charm, clarity, and interest using a rubric. In this study, the children's spoken and written selfconstructed narratives were categorized based upon the four-point scale. Educators blind to the students' language ability judged the narratives of the children with language impairments to have a lower overall quality as compared to their peers. In general, the adolescents with language impairments produced stories with weaker descriptions, organization, and/or missing episodic elements. In sum, deficits related to macrostructure (i.e., story grammar elements) and microstructure (e.g., clausal density, total number of words, number of different words, grammaticality, lexical density, etc.) have been observed in the narratives by students with language-based disorders beginning in the early elementary ages through adolescence.

Although observed differences in narrative macrostructure and microstructure have been examined in a range of research studies, research specific to the use of verbs (without additional analysis of tense changes or variations in syntax structure) between children with typical language and children with language disorders is limited. One study which did examine the use of metacognitive and metalinguistic verbs between these two groups was the previously mentioned study by Greenhalgh and Strong (2001). It was observed that the children with typical language skills exhibited higher averages for all literate language measures than those of the group with language impairment. However, the difference between the groups for metalinguistic and metacognitive verb use was not statistically significant. The authors proposed the reason for this finding was due to the overall limited verb use in the stories of both groups (Greenhalgh \& Strong, 2001).

One additional study examining verb use in students with language disorders did so in the context of conversation. Watkins et al. (1993) compared 100-word conversational samples from fourteen preschool aged children with specific language impairment to those of age-matched and 
language-matched typically developing peers. Significant differences were observed in the participants' verb type to token ratios. The children with language impairments relied on a smaller set of verbs than those with typical language. These results indicated that children aged five with a language impairment demonstrated less verb diversity in conversation than children with typical language at the age of three (Watkins et al., 1993).

While there is limited information regarding the use of verbs between children with typical language and their peers with language impairment, differences in narrative language abilities have been observed between those with and without language disorders. Narratives created by children with a language impairment often contain less detail, meaning there are syntactically less complex language structures used. Based upon this information, it could be hypothesized that the less complex, more concrete verb type (i.e., action verbs) is used more in narratives by children with a language impairment, while decontextualized language (i.e., mental and linguistic verbs) may be used more by children with typical language.

\section{Chapter II: Present Study}

\section{Purpose}

Given the limited information available regarding the use of action verbs, metacognitive verbs, and metalinguistic verbs, the present study was designed to determine the difference in verb use as a function of age within the context of oral narratives. Oral narratives were the focus of this study due to their importance in academic success. The difference in verb use by children with language impairment and their typically developing peers was also assessed. In summary, the present research study examined the following questions:

- Does the use of action, metacognitive, and metalinguistic verbs in oral narratives increase over time for students with typically developing language? 
- Is there a difference in the total use of different verb types (i.e., action, metalinguistic, and metacognitive) or number of different types of verbs used between children with typical language and language impairment?

Although there has been limited research specific to the use of verbs, it was expected that a pattern similar to the development of other forms of decontextualized language would be observed. Therefore, it was hypothesized that use of action, metacognitive, and metalinguistic verbs would increase with age both in overall quantity as well as number of different types. More specifically, it was expected that older students would utilize a greater number of literate language verbs (i.e., metacognitive and metalinguistic verbs) as compared to the younger students given the increased size of a student's lexicon over time and the longer trajectory of development previously observed.

Similarly, it was predicted that differences in use of all verb types, specifically metacognitive and metalinguistic verbs, would be noted in students with and without language impairment. Given evidence that the use of decontextualized language is associated with the production of complex syntax (Sun \& Nippold, 2012), it was hypothesized that children with language impairment would use fewer metacognitive and metalinguistic verbs in their narratives. In addition, less variety in the types of verbs utilized was expected.

\section{Chapter III: Methods}

The project was reviewed by the Institutional Review Board for human subject research at a midwestern university and classified as nonhuman subject research because the oral narrative samples had already been gathered as part of a previous project. 


\section{Participants}

A total of 123 students, including those with typical language and those with a languagebased disorder, were included in this study. All students with typical language (TL) were included in the analysis for the first research question, resulting in a total of 85 students between $5 ; 1$ and 14;4 years of age. To answer the second research question, students who had previously been diagnosed with a language learning impairment (LLI) were age-matched to students who were typically developing (TD). Students were identified as having a language learning impairment if they had a previous diagnosis of reading and/or writing learning disorders as well as those who scored at or below $1 \mathrm{SD}$ from the mean on at least one subtest of the Test of Narrative Language, $2^{\text {nd }}$ edition $(T N L-2)$. Those identified as having typical language received an overall score of a 92 or greater on the $T N L-2$. Students with LLI were matched with two typically developing peers of the same gender. Therefore, a total of 114 students (76 with typical language, 38 with a language disorder) were included in these analyses. The matching process involved a bracketing strategy, where the participant with LLI was matched with two typically developing students, one no more than three months below the age of the student with LLI and one student no greater than three months older.

\section{Procedure}

Students between the ages of five and fourteen years completed the narrative generation task during the standardization process of the Test of Narrative Language, $2^{\text {nd }}$ edition (TNL-2). From these samples, the participants" "Alien Story," a generation task using a single-episode picture, was transcribed and analyzed utilizing a consensus procedure for transcription and based upon the guidelines of Systematic Analysis of Language Transcription (SALT) software. After each sample was transcribed by a trained examiner, a second examiner checked the transcription 
for errors while listening to the audio sample. Differences were discussed and agreement was obtained for each narrative.

The transcriptions of the "Alien Story" were then coded by the author in regard to the use of action, metacognitive, and metalinguistic verbs. This coding system accounted for all instances of action verbs (AV), metacognitive verbs (MCV), and metalinguistic verbs (MLV) used and also took into account the number of different verbs used for each of these types. For instance, all uses of action verbs were coded as [AV], and the number of different action verbs used was totaled (NDAV, NDMCV, NDMLV). The additional measures of Subordination Index (SI), Number of Total Words (NTW), Number of Different Words (NDW), and Total Number of T-Units were obtained using SALT software. The lead coder and second coder were blinded to the participants' ages and language status.

\section{Data Analysis}

Reliability of coding using a line-by-line consensus coding was completed. Twenty percent of the samples were randomly selected and independently coded with $96 \%$ agreement in coding of verb types achieved. Analysis of the coded samples was completed using SALT (2019). To account for the possibility that the length of the sample might impact total verb counts, a new variable, verb rate, was calculated. The number of verbs used (action, metacognitive, or metalinguistic) was divided by the number of total T-units for each participants' story to yield a verb rate (AVR, MCVR, MLVR).

The first step in the analysis was to check the data to determine if there were outliers within the pool. The results indicated that one typically developing student was significantly different from the others related to the length of the story provided. Specifically, this student had $103 \mathrm{~T}$-units in his narrative, $50 \mathrm{~T}$-units more than the closest participant. Further examination of 
the data related to the average length of sample, average utterance length, and other measures with and without this participant were significantly different. Therefore, the data from this participant were excluded from the analyses. This decreased the number of participants from question one to 84 and the total number of participants from question two to 113 (75 students with typical language and 38 students with a language disorder).

The results of question one were analyzed using Pearson correlation coefficient testing. The data for question two were analyzed utilizing Mann-Whitney U tests. Due to the fact that six tests were run, a Bonferroni adjustment was performed to correct for the greater possibility of a Type I error. Assuming the alpha level of $p=0.05$, a new significance level of .008 was determined by calculating .05 divided by six, the number of tests run. Therefore, any reported $p$ value less than .008 was deemed statistically significant.

\section{Chapter IV: Results}

The 84 participants with typical language generally were normally distributed in regard to the dependent variables (AVR, MCVR, MLVR, NDAV, NDMCV, NDMLV). To report the descriptive data, they were separated into three age groups. The first age group, 5;0 to 7;11, included fifteen participants (Table 4.1a). This group of participants exhibited an average rate of 0.82 action verbs per utterance along with 0.09 rate of metacognitive verbs and 0.10 rate of metalinguistic verbs. When examining the number of different verbs used in the samples, this age group used an average of seven different action verbs and one different metacognitive and metalinguistic verb. The next age group included 53 participants, 8;0 to 10;11 years of age (Table 4.1b). The average use of action verbs increased in this group, with an average rate of 0.94 used. 
The last age group analyzed was participants ages 11;0-14;4 (Table 4.1c). The average rate of verb use from these 16 participants increased in this group as well with an average rate of 0.98 action verbs used, 0.14 metacognitive verb rate, and 0.16 of metalinguistic verbs used per utterance.

Table 4.1a Descriptive data for Question 1 participants ages 5;0-7;11, $n=15$

\begin{tabular}{|c|c|c|c|c|}
\hline Measure & Minimum & Maximum & Mean & $\begin{array}{c}\text { Standard } \\
\text { Deviation }\end{array}$ \\
\hline Total T-units & 4.00 & 36.00 & 13.73 & 8.86 \\
\hline MLUm & 6.20 & 11.25 & 7.94 & 1.32 \\
\hline NTW & 28.00 & 262.00 & 97.93 & 63.36 \\
\hline NDW & 25.00 & 113.00 & 51.93 & 23.69 \\
\hline SI & 1.00 & 1.50 & 1.22 & 0.17 \\
\hline AVR & 0.38 & 1.25 & 0.82 & 0.22 \\
\hline MCVR & 0.00 & 0.38 & 0.09 & 0.11 \\
\hline MLVR & 0.00 & 0.52 & 0.10 & 0.14 \\
\hline NDAV & 3.00 & 17.00 & 7.07 & 3.95 \\
\hline NDMCV & 0.00 & 4.00 & 0.87 & 1.13 \\
\hline NDMLV & 0.00 & 2.00 & 0.87 & 0.74 \\
\hline
\end{tabular}

Note: $\mathrm{MLUm}=$ mean length of utterance in morphemes; NTW= number of total words; $\mathrm{NDW}=$ number of different words; $\mathrm{SI}=$ subordination index; $\mathrm{AVR}=$ action verb rate; $\mathrm{MCVR}=$ metacognitive verb rate; $\mathrm{MLVR}=$ metalinguistic verb rate; $\mathrm{NDAV}=$ number of different action verbs; NDMCV= number of different metacognitive verbs; NDMLV= number of different metalinguistic verbs

Table 4.1b Descriptive data for Question 1 participants ages 8;0-10;11, $n=53$

\begin{tabular}{|c|c|c|c|c|}
\hline Measure & Minimum & Maximum & Mean & $\begin{array}{c}\text { Standard } \\
\text { Deviation }\end{array}$ \\
\hline Total T-units & 6.00 & 53.00 & 17.47 & 9.72 \\
\hline MLUm & 5.96 & 12.67 & 8.98 & 1.52 \\
\hline NTW & 44.00 & 392.00 & 138.58 & 73.62 \\
\hline NDW & 28.00 & 162.00 & 70.36 & 27.31 \\
\hline SI & 1.00 & 1.79 & 1.29 & 0.16 \\
\hline AVR & 0.43 & 1.71 & 0.94 & 0.32 \\
\hline MCVR & 0.00 & 0.33 & 0.12 & 0.09 \\
\hline MLVR & 0.00 & 0.40 & 0.13 & 0.11 \\
\hline NDAV & 3.00 & 25.00 & 10.23 & 4.66 \\
\hline NDMCV & 0.00 & 5.00 & 1.60 & 1.28 \\
\hline NDMLV & 0.00 & 4.00 & 1.13 & 0.88 \\
\hline
\end{tabular}


Note: $\mathrm{MLUm}=$ mean length of utterance in morphemes; NTW= number of total words; $\mathrm{NDW}=$ number of different words; $\mathrm{SI}=$ subordination index; $\mathrm{AVR}=$ action verb rate; $\mathrm{MCVR}=$ metacognitive verb rate; $\mathrm{MLVR}=$ metalinguistic verb rate; $\mathrm{NDAV}=$ number of different action verbs; NDMCV= number of different metacognitive verbs; NDMLV= number of different metalinguistic verbs

Table 4.1c Descriptive Data for Question 1 participants ages 11;0-14;4, $n=16$

\begin{tabular}{|c|c|c|c|c|}
\hline Measure & Minimum & Maximum & Mean & $\begin{array}{c}\text { Standard } \\
\text { Deviation }\end{array}$ \\
\hline Total T-units & 10.00 & 48.00 & 23.00 & 10.11 \\
\hline MLUm & 7.62 & 16.09 & 10.42 & 2.27 \\
\hline NTW & 91.00 & 469.00 & 220.00 & 116.64 \\
\hline NDW & 56.00 & 175.00 & 102.38 & 38.35 \\
\hline SI & 1.17 & 1.66 & 1.36 & 0.14 \\
\hline AVR & 0.52 & 1.50 & 0.98 & 0.26 \\
\hline MCVR & 0.00 & 0.33 & 0.14 & 0.10 \\
\hline MLVR & 0.00 & 0.30 & 0.16 & 0.09 \\
\hline NDAV & 8.00 & 26.00 & 13.69 & 5.57 \\
\hline NDMCV & 0.00 & 4.00 & 2.19 & 1.33 \\
\hline NDMLV & 0.00 & 4.00 & 2.19 & 1.28 \\
\hline
\end{tabular}

Note: $\mathrm{MLUm}=$ mean length of utterance in morphemes; NTW= number of total words; $\mathrm{NDW}=$ number of different words; $\mathrm{SI}=$ subordination index; $\mathrm{AVR}=$ action verb rate; $\mathrm{MCVR}=$ metacognitive verb rate; $\mathrm{MLVR}=$ metalinguistic verb rate; NDAV = number of different action verbs; NDMCV= number of different metacognitive verbs; NDMLV= number of different metalinguistic verbs

The data analyzed for research question two included 75 participants with typical language and 38 participants with a language impairment. The data of the sample measures from the two different disorder types is seen below (Table 4.2a and Table 4.2b). The participants with typical language exhibited an average NTW of 143 and NDW of 72, whereas those with a language impairment exhibited lower measures at an average NTW of 71 and an average NDW of 40 . 
Table 4.2a Descriptive data for age-matched students with typical language, $n=75$

\begin{tabular}{|c|c|c|c|c|}
\hline Measure & Minimum & Maximum & Mean & $\begin{array}{c}\text { Standard } \\
\text { Deviation }\end{array}$ \\
\hline Total T-units & 4.00 & 53.00 & 17.56 & 9.81 \\
\hline MLUm & 5.96 & 16.09 & 9.03 & 1.76 \\
\hline NTW & 28.00 & 458.00 & 143.32 & 85.86 \\
\hline NDW & 25.00 & 167.00 & 71.63 & 31.79 \\
\hline SI & 1.00 & 1.79 & 1.29 & 0.17 \\
\hline AVR & 0.43 & 1.71 & 0.94 & 0.29 \\
\hline MCVR & 0.00 & 0.38 & 0.12 & 0.10 \\
\hline MLVR & 0.00 & 0.52 & 0.13 & 0.11 \\
\hline NDAV & 3.00 & 25.00 & 10.21 & 4.96 \\
\hline NDMCV & 0.00 & 5.00 & 1.56 & 1.32 \\
\hline NDMLV & 0.00 & 4.00 & 1.27 & 1.00 \\
\hline
\end{tabular}

Note: $\mathrm{MLUm}=$ mean length of utterance in morphemes; NTW= number of total words; $\mathrm{NDW}=$ number of different words; $\mathrm{SI}=$ subordination index; $\mathrm{AVR}=$ action verb rate; $\mathrm{MCVR}=$ metacognitive verb rate; $\mathrm{MLVR}=$ metalinguistic verb rate; $\mathrm{NDAV}=$ number of different action verbs; NDMCV= number of different metacognitive verbs; NDMLV= number of different metalinguistic verbs

Table 4.2b Descriptive data for students with language impairment, $n=38$

\begin{tabular}{|c|c|c|c|c|}
\hline Measure & Minimum & Maximum & Mean & $\begin{array}{c}\text { Standard } \\
\text { Deviation }\end{array}$ \\
\hline Total T-units & 3.00 & 22.00 & 9.92 & 4.99 \\
\hline MLUm & 4.25 & 15.10 & 7.87 & 1.88 \\
\hline NTW & 11.00 & 167.00 & 71.39 & 40.62 \\
\hline NDW & 11.00 & 87.00 & 40.26 & 17.55 \\
\hline SI & 0.92 & 1.70 & 1.19 & 0.20 \\
\hline AVR & 0.17 & 1.50 & 0.76 & 0.33 \\
\hline MCVR & 0.00 & 0.40 & 0.08 & 0.11 \\
\hline MLVR & 0.00 & 0.70 & 0.13 & 0.17 \\
\hline NDAV & 1.00 & 14.00 & 5.55 & 3.40 \\
\hline NDMCV & 0.00 & 2.00 & 0.58 & 0.72 \\
\hline NDMLV & 0.00 & 2.00 & 0.74 & 0.72 \\
\hline
\end{tabular}

Note: $\mathrm{MLUm}=$ mean length of utterance in morphemes; NTW= number of total words; $\mathrm{NDW}=$ number of different words; $\mathrm{SI}=$ subordination index; $\mathrm{AVR}=$ action verb rate; $\mathrm{MCVR}=$ metacognitive verb rate; $\mathrm{MLVR}=$ metalinguistic verb rate; NDAV $=$ number of different action verbs; NDMCV= number of different metacognitive verbs; NDMLV= number of different metalinguistic verbs 
Similarly, the measures of verb use between these two groups were different. When examining the rate of total verb use per utterance, the children with typical language exhibited higher numbers, with average rates of 0.94 action verbs, 0.12 metacognitive verbs, and 0.13 metalinguistic verbs used. The children with language impairment used an average rate of 0.76 action verbs, 0.08 metacognitive verbs, and 0.13 metalinguistic verbs. In regard to the number of different verbs used in each language sample, the children with typical language used an average of 10 different action verbs, two metacognitive, and one metalinguistic. In a similar pattern as the rate of total verbs used, the children with language impairment used a fewer variety of verbs at an average of six different action verbs and one different metacognitive and metalinguistic verb.

\section{Research Question 1}

Correlation coefficient analyses were used to determine the relationship between the growth in age of participants and their use of action verbs, metacognitive verbs, and metalinguistic verbs, measured as a rate per total utterances. Based on this analysis, there were weak but statistically significant positive correlations between age in months and the rate of action verbs, $r(84)=.242, p<.05$ and metacognitive verbs, $r(84)=.230, p<.05$. This test also revealed a statistically significant correlation between age in months and rate of metalinguistic verbs, $r(84)=.248, p>.05$. In addition, a significant positive correlation was observed between the metacognitive and metalinguistic types, $r(84)=.235, p<.05$. No significant correlations were observed between action verbs and metalinguistic or metacognitive verb rates (Table 4.3a).

Correlations between the number of different action, metacognitive, and metalinguistic verbs used revealed stronger correlations between all verb types. Weak to moderate, positive correlations were observed between age in months and the use of different action verbs, $r(84)=$ $.468, p<.01$ and metacognitive verbs, $r(84)=.400, p<.01$. A moderate, positive correlation was 
observed between age in months and the number of different metalinguistic verbs used, $r(84)=$ $.471, p<.01$. In addition, significant correlations were revealed between the three verb types, with the strongest correlation between the number of different action verbs and the number of different metacognitive verbs, $r(84)=.580, p<.01$ (Table $4.3 \mathrm{~b})$.

Table 4.3a Correlation coefficient data for rates of total verb use per utterance

\begin{tabular}{|c|c|c|c|}
\hline & Action Verb Rate & $\begin{array}{c}\text { Metacognitive Verb } \\
\text { Rate }\end{array}$ & $\begin{array}{c}\text { Metalinguistic Verb } \\
\text { Rate }\end{array}$ \\
\hline Age in Months & $.242^{*}$ & $.230^{*}$ & $.248^{*}$ \\
\hline Action Verb Rate & & .193 & -.027 \\
\hline Metacognitive Verb Rate & & & $.235^{*}$ \\
\hline
\end{tabular}

$*=$ sig. at .05 level; $* *=$ sig. at .01 level

Table 4.3b Correlation coefficient data for number of different verbs used

\begin{tabular}{|c|c|c|c|}
\hline & $\begin{array}{c}\text { Number of Different } \\
\text { Action Verbs }\end{array}$ & $\begin{array}{c}\text { Number of Different } \\
\text { Metacognitive Verbs }\end{array}$ & $\begin{array}{c}\text { Number of Different } \\
\text { Metalinguistic Verbs }\end{array}$ \\
\hline Age in Months & $.468^{* *}$ & $.400^{* *}$ & $.471^{* *}$ \\
\hline $\begin{array}{c}\text { Number of Different } \\
\text { Action Verbs }\end{array}$ & & $.580^{* *}$ & $.535^{* *}$ \\
\hline $\begin{array}{c}\text { Number of Different } \\
\text { Metacognitive Verbs }\end{array}$ & & & $.426^{* *}$ \\
\hline
\end{tabular}

$*=$ sig. at .05 level; $* *=$ sig. at .01 level

\section{Research Question 2}

Non-parametric tests were conducted to analyze the participants' oral narrative language samples due to the data sets violating the assumption of normality required for an analysis of variance (ANOVA). A Mann-Whitney $U$ test was run to determine if there were differences between the rate of action verb use for children with typical language (TL) as compared to their peers with a language learning impairment (LLI). Distributions of the engagement scores for the two groups were not similar, as assessed by visual inspection. Engagement scores for children with TL (mean rank $=62.71)$ and children with LLI (mean rank $=45.72)$ were approaching statistical significance, $U=996.5, z=-2.608, p=.009$. Similar Mann-Whitney $\mathrm{U}$ tests for the rate of metacognitive verb and metalinguistic verb use were run between the two groups. There were 
no significant differences observed in the rate of metacognitive verbs used between the children with TL (mean rank= 61.94) and peers with LLI (mean rank= 47.25), $U=1054.50, z=-2.300, p=$ .021 , or between the rate of metalinguistic verbs used by the children with TL (mean rank= 59.57) and those with LLI (mean rank= 51.92), $U=1232.00, z=-1.190 p=.234$. These results suggested that although the children with typical language used a greater rate of these differing verb types in their narratives, the difference between groups was not statistically significant.

The number of different verbs for each verb type used in the narratives between both participant groups was also analyzed using Mann-Whitney U tests. Distributions of the engagement scores from these three tests were not similar, as assessed by visual inspection. Therefore, results are reported using mean ranks. The engagement scores for number of different action verbs used by children with TL (mean rank $=68.07$ ) was significantly higher than that of children with LLI (mean rank= 35.16), $U=595.00, z=-5.067, p<.001$. Similarly, the number of different metacognitive verbs used by children TL (mean rank= 65.46) was significantly greater than that of their peers with LLI (mean rank= 40.30), $U=790.50, z=-4.018, p<.001$. A statistically significant difference in the number of different metalinguistic verbs used was also observed, higher for children with TL (mean rank= 62.59) than children with LLI (mean rank= 45.97), $U=1006.00, z=-2.688, p=.007$. These results suggested that those with typical language used a significantly greater variety of verbs across all three types in their oral narratives when compared to students with a language learning impairment.

These findings were analyzed further to identify effect sizes of the differing verb usage. Although the rate of action verbs used between children with TL and children with LLI was observed to be approaching statistical significance $(p=.009)$, the effect size for this analysis $(d=$ 
$0.61)$ was found to exceed Cohen's convention for a moderate effect $(d=0.50)$. This effect size indicated that the use of action verbs between groups is clinically meaningful.

In regard to the variety of verbs utilized in their samples, the effect sizes for the significant findings in the number of different verbs used for action, metacognitive, and metalinguistic verbs were also calculated. The effect sizes for the number of different action verbs used $(d=1.05)$ and the number of different metacognitive verbs used $(d=0.86)$ between children with TL and children with LLI were both found to exceed Cohen's convention for a large effect $(d=0.80)$. The effect size for the number of different metalinguistic verbs used $(d=$ 0.58) was found to be moderate and clinically meaningful as indicated by Cohen's convention for a moderate effect $(d=0.50)$ (Cohen, 1977).

\section{Chapter V: Discussion}

The purpose of this study was to examine the use of different verb types with age-related growth as well as between participant groups, children with typical language and their peers with a language learning impairment. The findings of this study indicated significant, positive correlations between the use of action verbs, metalinguistic verbs, and metacognitive verbs and age in months of the participants. This significant finding indicated that as children get older,

they use more of every verb type per utterance in their oral narratives. Positive, significant correlations were also observed between age and the number of different verbs used, meaning that as children get older, they also use a larger variety of verbs in their narratives.

In relation to the second research question, the rates of total verbs used between children with typical language and those with a language learning impairment were not significant. However, there were significant differences observed in the variety of verbs used between 
groups. The children with typical language used a greater number of different action, metacognitive, and metalinguistic verbs in their narratives.

\section{Verb Development and Use by Students with Typical Language and Disorders}

As previously discussed, differing verb types are used in narratives to initiate events, convey character dialogue, and increase syntactic complexity. Certain verb types, metalinguistic and metacognitive verbs, have been observed to emerge later in childhood, with full comprehension and development occurring throughout adolescence and early adulthood (Papafagou et al., 2007; Astington \& Olson, 1987; Sun \& Nippold, 2012; Nippold, 2016). Given this research about verb acquisition, it is understandable that the same pattern was observed in the present study with the use of action, metacognitive, and metalinguistic verbs increasing over time throughout participants ages 5;0 to 14;4. Therefore, these results support the present hypothesis that the use of verbs would increase with age for both the quantity and variety of verbs used.

The results of the present study are similar to several previously mentioned research studies regarding the use of these differing verb types in narrative discourse. Sun \& Nippold (2012) observed children aged 17 to use more mental and linguistic verbs in written narratives than children aged younger at 11 and 14 . With that said, the current results were different than a few other previous studies. For instance, Greenhalgh \& Strong (2001) and Fuste-Hermmann et al. (2006) found no significant difference in the use of mental state verbs within narrative retells across age groups. One theory to explain the lack of verb use differences, as mentioned by Greenhalgh \& Strong (2001), may have been related to the task selected. It is possible that a narrative retell may not be sensitive to growth over time because the sample limits the verb usage 
given the task is a retell as compared to a generation task which permits the participant more freedom to self-select the verbs to use.

The previous study, Greenhalgh \& Strong (2001), differed from the current research in that the participants provided a narrative retell, as compared to self-constructed narrative used in the current study. It is possible that there were insignificant findings with the retell because this type of narrative was short and had limited content, which posed ceiling effects for the older children with typical language. Additionally, the actual story chosen, Frog Where Are You, may have specifically limited the use of decontextualized language, if for instance it did not contain many of these verbs to then be used in the participants' retells. This is a study limitation to be discussed in further detail.

Regarding the second research question of the present study, there has been limited research to examine the differences in verb use between disorder types. However, the findings of this thesis showing that a fewer variety of verbs was used by children with language impairment as compared to their peers with typical language were expected due to what is known about the quality of narratives between these two groups. Children with a language impairment have been observed to exhibit less complex, disorganized narratives (Merritt \& Liles, 1987; Fey et al., 2004, Reed et al., 2007), and it is known that verbs can lead to more complex syntax and more developed macrostructure elements. Therefore, the data showing a greater number and variety of verbs by children with typical language compared to children with language impairment is expected because their narratives are typically more proficient.

\section{Clinical Implications}

An important part for clinicians when addressing narratives in speech-language intervention is identifying the appropriate treatment targets. With the information from this 
study, it is evident that children with a language learning impairment use a fewer variety of action, metacognitive, and metalinguistic verbs in their stories. Verbs play an integral component in the development of story grammar elements and the complexity of a narrative, and therefore, would be beneficial to target within narrative intervention. Aside from targeting verbs specifically, these results indicate that an appropriate target for children with LLI could be the breadth of their vocabulary, since they were observed to use a limited number of verbs in their narratives as compared to their typically developing peers. For instance, it would be beneficial to target synonyms or introduce semantic mapping strategies in intervention in order to increase their word knowledge. Increasing the number of different verbs used in a narrative would increase its quality and descriptiveness, an area of weakness identified in the narratives of children with LLI (McFadden \& Gillam, 1996; Fey et al., 2004; Reed et al., 2007). These targets in treatment, expanding students' vocabulary, may also improve reading comprehension or oral expression altogether.

These findings also provide insight into the development of action, metacognitive, and metalinguistic verbs. Research historically has shown that action verbs are acquired earlier than the other verb types. However, this present study indicated that action verb use continued to increase with growth in age, as did the other verb types. There is an argument to be made about whether this growth was due to an actual increase in verb use with age or an increase in narrative complexity, meaning more action verbs must be used as clausal density increases. Nonetheless, these findings provide valuable information to clinicians regarding intervention targets.

\section{Limitations and Future Research}

As previously mentioned, the impact of the task is an area of concern that requires further analysis. It is possible that a narrative writing task as opposed to an oral task would elicit more 
literate language verbs or a larger variety of verbs because it is more complex. Another taskrelated question needing further evaluation is that of a retell versus generation. A narrative retell task may impose a ceiling effect on measures such as the number of verbs to be used making it more difficult to discern a student with a language disorder from a typically developing student. In contrast, a self-generated narrative or even a narrative generated based upon a picture or series of pictures, as seen with the "Alien Story" task of this current study, could allow the student to use a wider variety of language. To learn more about these possible task discrepancies, studies should be performed to examine the use of action verbs, metacognitive verbs, and metalinguistic verbs in both narrative writing and oral tasks within the same group of participants, including both those with typical language and those with language-based disorders. For clinicians working with students with language impairments, providing critical information about the impact of the task in identifying deficits could assist them in selecting an appropriate task during evaluation as well as when monitoring progress in treatment.

\section{Conclusions}

The results from this study indicated that the rate of action, metacognitive, and metalinguistic verbs used significantly increased with growth in age. Also, as predicted, the number of different verbs for each of these types significantly increased as the age of participants increased. When analyzing verb use between language abilities, children with typical language used more of each verb type, but the difference between this use by children with language impairment was not significant. Lastly, children with language impairment did not use as much variety of each verb type as children with typical language in their narratives. These findings support hypotheses that verb development continues through early adolescence and that the narratives of children with LLI have less variation in the types of action, metacognitive, and 
metalinguistic verbs utilized. Future research is needed to determine the impact of the task presented as well as to further analyze verb use in narrative discourse given the limited research completed thus far. 


\section{References}

Akhtar, N., \& Tomasello, M. (2000). The social nature of words and word learning. In Golinkoff, R., \& Hirsh-Pasek, K. (Eds)., Becoming a Word Learner: A debate on lexical acquisition. Oxford University Press.

Astington, J., \& Pelletier, J. (2003). Theory of mind and metacognitive vocabulary development in first and second languages. Unpublished manuscript, University of Toronto

Cohen, J. (1977). Statistical power analysis for behavioral sciences (revised ed.). New York: Academic Press.

Curenton, S., Craig, M., \& Flanigan, N. (2008). Use of decontextualized talk across story contexts; How oral storytelling and emergent reading can scaffold children's development. Early Education and Development, 19(1), 161-187.

doi:10.1080/10409280701839296

Curenton, S., \& Justice, L. (2004). African American and Caucasian preschoolers' use of decontextualized language: Literate language features in oral narratives. Language, Speech, and Services in Schools, 35, 240-253. doi:0161-1461/04/3503-0240

Fey, M., Catts, H., Proctor-Williams, K., Tomblin, J., \& Zhang, X. (2004). Oral and written story composition skills of children with language impairment. Journal of Speech, Language, and Hearing Research, 47, 1301-1318. doi:1092-4388/04/4706-1301

Fuste-Hermann, B., Silliman, E., Bahr, R., Fasnacht, K., \& Federico, J. (2006). Mental state verb production in the oral narratives of English-and-Spanish-speaking preadolescents: An exploratory study of lexical diversity and depth. Learning Disabilities Research \& Practice, 21(1), 44-60. 
Gillam, R., \& Johnston, J. (1992). Spoken and written language relationships in language/learning-impaired and normally achieving school-age children. Journal of Speech and Hearing Research, 35, 1303-1315.

Gillam, R., \& Pearson, N. (2017). Test of Narrative Language (2 ${ }^{\text {nd }}$ ed.). Austin, TX: Pro-Ed

Golinkoff, R., \& Hirsh-Pasek, K. (2008). How toddlers begin to learn verbs. Trends in Cognitive Sciences, 12(10), 397-403. doi: 10.1016/j.tics.2008.07.003

Greenhalgh, K., \& Strong, C. (2001). Literate language features in spoken narratives of children with typical language and children with language impairments. Language, Speech, and Hearing Services in Schools, 32, 114-125. doi:0161-1461/01/3202-0114

Hirsh-Pasek, K., \& Golinkoff, R. (2006). Action meets word: How children learn verbs. Oxford University Press.

Justice, L., \& Ezell, H. (2016). The syntax handbook: Everything you learned about syntax...but forgot ( $2^{\text {nd }}$ ed.). Austin, TX: Pro-Ed

Mayer, M. (1969). Frog, where are you? New York, NY: Dial Press

McFadden, T., \& Gillam, R. (1996). An examination of the quality of narratives produced by children with language disorders. Language, Speech, and Hearing Services in Schools, 27(1), 48-56

Merritt, D., \& Liles, B. (1987). Story grammar ability in children with and without language disorders: Story generation, story retelling, and story comprehension. Journal of Speech and Hearing Research, 30, 539-551

National Governors Association Center for Best Practices, \& Council of Chief State School Officers. (2010). Common Core State Standards for English language arts. Retrieved from: http://www.corestandards.org/ELA-Literacy/ 
Nippold, M. (2016). Later language development: School-age children, adolescents, and young adults (4th ed.). Austin, TX: Pro-Ed

Nippold, M., Frantz-Kaspar, M., Cramond, P., Kirk, C., Hayward-Mayhew, C., \& MacKinnon, M. (2015). Critical thinking about fables: Examining language production and comprehension in adolescents. Journal of Speech, Language, and Hearing Research, 58, 325-335.

Nippold, M., Vigeland, L., \& Frantz-Kaspar, M. (2017). Metacognitive verb production in adolescents: The link to complex syntax. Clinical Linguistics and Phonetics, 31(10), 761 776. doi:10.1080/02699206.2017.1318953

Owens, R. (2016). Language development: An introduction $9^{\text {th }}$ edition. Pearson.

Papafragou, A., Cassidy, K., \& Gleitman, L. (2006). When we think about thinking: The acquisition of belief verbs. Cognition, 105, 125-165. doi:10.1016/j.cognition.2006.09.008

Peskin, J. \& Astington, J.W. (2004). The effects of adding metacognitive language to story texts. Cognitive Development, 19, 253-273. doi:10.1016/j.cogdev.2004.01.003

Reed, V., Patchell, F., Coggins, T., \& Hand, L. (2007). Informativeness of the spoken narratives of younger and older adolescents with specific language impairment and their counterparts with normal language. Clinical Linguistics \& Phonetics, 21(11-12), 953-960

Schneider, W. (2008). The development of metacognitive knowledge in children and adolescents: Major trends and implications for education. Mind, Brain, and Education, 2(3), 114-121

Schwanenflugel, P., \& Henderson, R. (1998). Developing organization of mental verbs and theory of mind in middle childhood: Evidence from extensions. Developmental Psychology, 34(3), 512-524. doi:0012-1649/98/3.00 
Scott, C., \& Windsor, J. (2000). General language performance measures in spoken and written narrative and expository discourse of school-age children with language learning disabilities. Journal of Speech, Language, and Hearing Research, 43(2), 324-339

Sun, L., \& Nippold, M. (2012). Narrative writing in children and adolescents: Examining the literate lexicon. Language, Speech, and Hearing in Schools, 43, 2-13. doi:10.1044/01611461(2011/10-0099)

Valle, A., Massaro, D., Castelli, I., \& Marchetti, A. (2015). Theory of mind development in adolescence and early adulthood: The growing complexity of recursive thinking ability. Europe's Journal of Psychology, 11(1), 112-124. doi:10.5964/ejop.v11i1.829

Van Dijk, T. (1975). Action, Action Description, and Narrative. New Literary History, 6(2), 273294. doi:10.2307/468420

Watkins, R., Rice, M., \& Moltz, C. (1993). Verb use by language-impaired and normally developing children. First Language, 13(7), 133-143. https://doi.org/10.1177/014272379301303708 